\title{
Sultan Qaboos University in Oman
}

\author{
By Harvey Varnet \\ Library Coordinator \\ Sultan Qaboos University \\ Muscat, Sultanate of Oman
}

\section{A modern library facility under construction in a more peaceful part of the Middle East.}

$\mathbf{H}$ ello from Oman! Where is Oman, did you say? That's the same question I asked a little over a year ago when Richard Palmer of Simmons College told me about the plans being made for Sultan Qaboos University. Sultan Qaboos bin Said is the ruler of the Sultanate of Oman, the second largest country - after Sa'udi Arabia-located on the Arabian Peninsula's southeast coast. Oman occupies an area of about 272,000 square kilometers (106,000 square miles). To the west Oman is bordered by the United Arab Emirates and Sa'udi Arabia, and to the south by the People's Democratic Republic of Yemen.

Oman is divided into several distinct geographic zones. The most fertile part of the country is the Batinah coastal plain stretching from the UAE border at Khatmat al'Malaha for $300 \mathrm{~km}$ (190 miles) to the Muscat area. The Batinah plain is an almost unbroken belt of cultivation up to $30 \mathrm{~km}$ (20 miles) in width between the sea and mountains. Across the northern section of the Sultanate runs the Hajjar mountain range, which reaches 3,075 meters $(10,250 \mathrm{feet})$ at its highest point, the Jebel Shams. Between the northern area and the Dhofar province lies a large stretch of desert, sand dune, and stony plain. Musandam, farther north and separated from the rest of the country, is extremely rocky and isolated with sheer cliffs dropping down to the sea and almost no cultivable land.

Oman's climate varies considerably from region to region. During the summer period from April to October the coastal area is very hot and humid,
Muscat regularly recording temperatures of $45^{\circ} \mathrm{C}$. $\left(112^{\circ}\right.$ F.) with $90 \%$ humidity. In the cooler months, November-March, daytime temperatures in the capital area drop to a pleasant $20-30^{\circ} \mathrm{C}$. and air conditioning is no longer necessary. In the interior it is hot and dry with the exception of some higher locations where it is temperate throughout the year. The southern region is also more temperate, although heavy rains fall between June and October. Elsewhere rainfall is low and irregular.

That's enough tourist information, except to say that it is not all desert here and the country is starkly beautiful.

In 1980 the Sultan announced that a modern, technologically-oriented university would be constructed, to be opened in the Fall of 1986. A Foundation Committee was formed that included Omani, British, American, and other scholars. The outline of the university was developed and the first five colleges were announced as Agriculture, Education and Islamic Sciences, Engineering, Medicine, and Science. These colleges are to be supported by a Library, a Medical Library, a Center for Educational Technology, a Computer Center, and a Language Center. Administration, works, housing for students and staff, sports areas, a cultural center, a student center, and a mosque complete the campus, located in Al'Khoudh, near Seeb about $40 \mathrm{~km}$ ( 25 miles) from Muscat.

Because of other successful work in the Middle East, Dick Palmer was hired in 1982 as the library consultant to prepare the initial brief. What devel- 
oped was a plan for a comprehensive library that will be fully automated, capable of seating 400 users, with a volume capacity of 200,000 . The relatively small volume capacity is possible because of the commitment on the part of the university to use the latest in telecommunications technology. The library building will also house the Center for Educational Technology (television, photography, au-

\section{Virtually any kind of}

\section{equipment is available} in Oman.

\section{dio, graphics) and the Computer Center.}

Coordinators were hired in 1982 and 1983 to begin implementation of the "briefs," and that's where I came in last September. As one soon learns, if you have a skill - expect it to be used. My initial library assignment was expanded and now I also oversee the development of the Computer Center, the Center for Educational Technology, the Medical Library, and some aspects of the College of Education (curriculum materials areas).

The main task at hand is to ensure that the consultant's reports are translated into buildings, staff, and equipment. As with any reports, there is a constant refining process when harsh reality greets an abstract concept. The case of the small TV studio that couldn't be expanded due to structural considerations makes this point. The solution worked out with the architects makes the area workable but not ideal.

So for me, this position is a continuous learning process. I work with paper created by consultants I hardly know (except Palmer) whose backgrounds are quite varied. The computer consultant is British; the library and CET consultants are American, one each from Massachusetts, Vermont, South Carolina, and California.

This brings up the problems with communications. The university contractor and the architects are U.K.-based. It is a never-ending logistics task to keep proper communication going from Oman to U.K. to U.S. Mail is always too slow; telexes are quick but never fully satisfactory; telephone calls are expensive and awkward due to time differences (nine hours difference from Eastern Standard to Oman). Somehow the work all gets done, but one has to learn to be comfortable with anxiety while waiting to hear from others far away.

There are other inherent challenges to be dealt with. How will we buy books? From the United States? Great Britain? In Oman? Local prices are steep. What about automated cataloging? What about periodicals? And what is the best way to establish formal relationships with libraries from which we will need to borrow materials (e.g., the British Library Lending Division, the Library of Congress, the National Library of Medicine)? When do I get to see all the appropriate people? Travel is expensive.

Another area that is evolving at the moment is whether we will equip the university through local vendors, international tenders, or some combination. The interesting point here is that there is virtually any kind of equipment available in Oman. This has been a pleasant surprise, for my expectations were that audiovisual, television, and computing equipment would be minimally available. Sometimes it is nice not to have your suspicions confirmed.

The staffing for the library will include twenty professional positions, several high-level technical positions, and a support staff that will bring the total to sixty. The organization will be a technical services/public services split, with the former concerned with all of the automation activities and the latter spending a great deal of time teaching students how to use a library.

This brings me to education. From three schools and a few hundred boys enrolled in 1970, the educational system has evolved to 473 schools and 142,866 students ( $35 \%$ female). There has been tremendous growth in thirteen years and more growth is projected. Until 1986 students will still need to leave Oman for a university education. When Sultan Qaboos University opens its doors in the Fall of 1986, there will be places in the first year for up to 582 qualified students from a pool of 3,000 potential candidates.

The students will encounter some difficulties. The university will be in effect a small city. Students from the interior will have to adjust to a new life style, and the style of education will require adjusting to as well. Students will be expected to be active learners. For most, their previous education will have been mostly passive, with the lecture or rote learning style prevalent. In addition, four of the five colleges will teach in English, a second language to Omanis.

Distance and communication delays are the most difficult things to cope with here. The pace of life is a bit more moderated: things do get done, but there is no need for over-compulsiveness. Americans may find it hard to slow down a bit.

One of the true bonuses is being in a country where people are so hospitable and friendly, and where you always feel safe. A ride to a village in the interior can wind up with your sharing coffee, dates, and world views with someone met by chance. Arab hospitality is legendary and deservedly so.

It is also of great intellectual benefit to work with a diverse group of people. We are Omani, British, American, New Zealander, Sudanese, Indian, and Danish. This is not your everyday U.S. 
group of academics. You acquire an education about various countries simply by discussing where you and your colleagues are from.

For me, the primary reason for coming to Oman was the opportunity to be in on the development of a university from the beginning. There aren't many such chances arising in the United States these days. It's very exciting to know that what you do is considered important and that your ideas will become operational realities in three years. You help to plan buildings and then you watch them go up. You organize staffing patterns and write job descriptions and then you begin to recruit. All that library coursework so long ago seems to come together when you are really starting from the beginning.

It's a long way from home, but coming to Oman has brought both personal and professional rewards. So far, all is going very well indeed.

\section{Library standards and accreditation in Puerto Rico}

More than one hundred librarians (including sixty academic librarians) gathered in San Juan, Puerto Rico, this past December to address the process of accreditation and library evaluation. The conference was sponsored by the Society of Librarians of Puerto Rico and organized by the Society's president, Dr. Luisa Vigo-Cepada.

Representatives of the Department of Education, the Council on Higher Education of Puerto Rico, the University of Puerto Rico, and the Association of College and Research Libraries each presented papers during the morning sessions. In the afternoon working groups addressed the issues of:

-improving the self-study process;

-improving the evaluation of Puerto Rican libraries;

-increasing the productivity and effectiveness of library programs and services;

- establishing norms and guides for different kinds of libraries in the light of the Puerto Rican re- ality; and

- recommendations to pertinent entities to be used in the evaluation and accreditation process.

On the following day ACRL's executive director, Dr. Julie Carroll Virgo, met with the library directors of the nine University of Puerto Rico campuses. The group systematically reviewed the ACRL College Library Standards and made some recommendations on their revision for the ACRL College Library Standards Committee hearings during the ALA Midwinter Meeting in Washington.

Virgo also spent an extended period of time with the University of Puerto Rico's acting president, Dr. Luis A. Sojo, discussing issues of mutual concern in higher education.

The hospitality and enthusiasm of our Puerto Rican colleagues encourage the development of still closer ties, perhaps through the formation of a Puerto Rican chapter of ACRL.

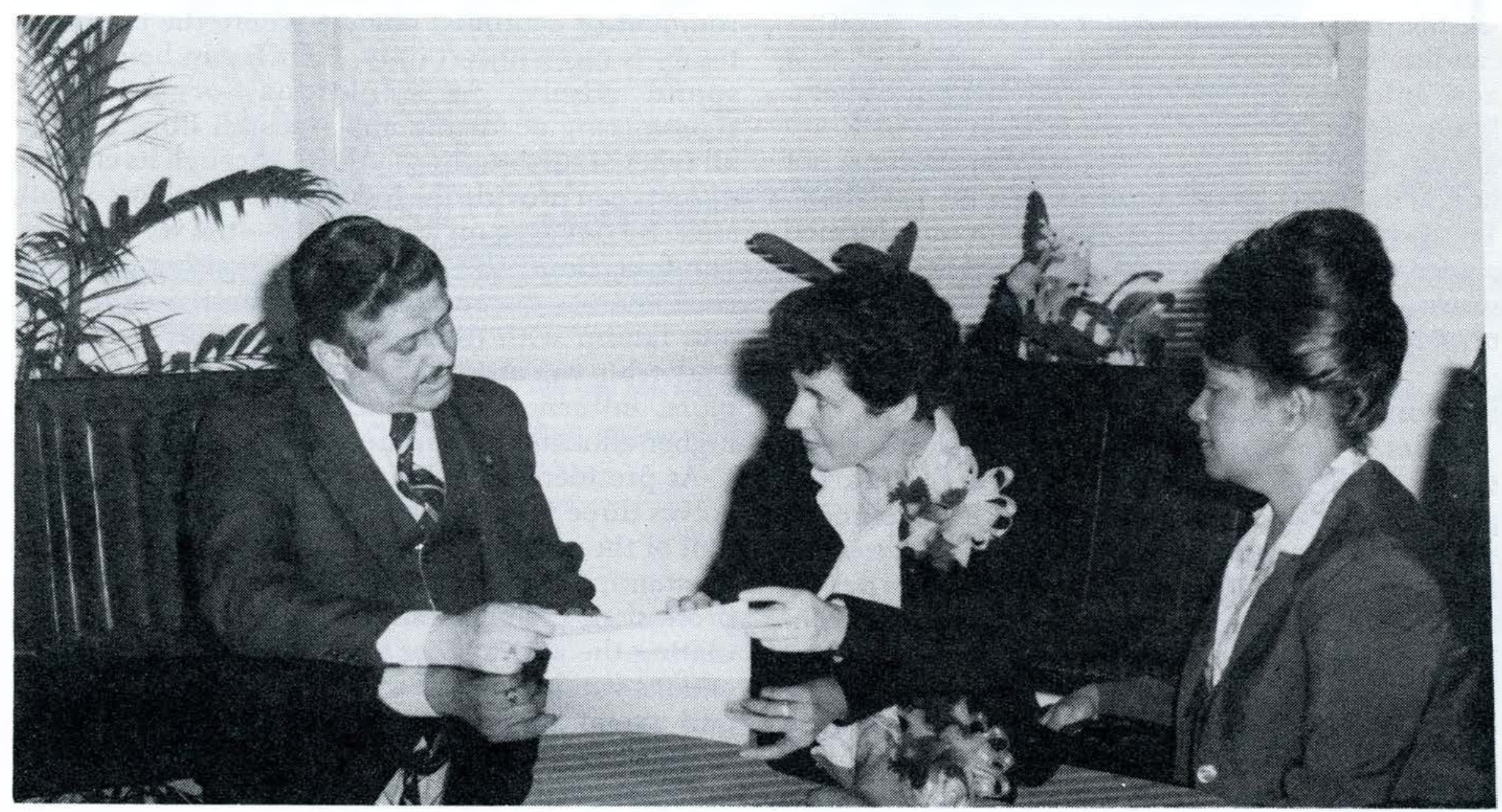

Dr. Luis A. Sojo, Dr. Julie Virgo, and Dr. Luisa Vigo-Cepada. 